JURNAL NUANSA INFORMATIKA

Volume 14 Nomor 1, Januari 2020
p-ISSN : 1858-3911, e-ISSN : 2614-5405

https://journal.uniku.ac.id/index.php/ilkom

\title{
CUSTOMER RELATIONSHIP MANAGEMENT DESIGN FOR PARENT SERVICE WEBSITE BASED IN STKIP MUHAMMADIYAH KUNINGAN
}

\author{
Dyah Puteria Wati ${ }^{1}$, Yoyo Zakaria ${ }^{2}$, Sofhian Fazrin Nasrulloh ${ }^{3}$ \\ Pendidikan Teknologi Informasi dan Komunikasi, STKIP Muhammadiyah Kuningan \\ Email:d.puteriawati@gmail.com
}

Dunia pendidikan saat ini berkembang sangat pesat, dimana suatu lembaga akan berhasil apabila didukung oleh teknologi informasi. Namun dukungan dari teknologi informasi saja tidak cukup, maka dari itu diperlukan tenaga ahli dan hal terpenting adalah komitmen manajemen untuk menjalin relasi dengan baik. Customer Relationship Management merupakan model menajemen yang dibutuhkan di STKIP Muhammadiyah Kuningan untuk menjalin hubungan yang baik antara lembaga dengan orangtua mahasiswa sehingga mampu meningkatkan kepuasan pelayanan orangtua. Salah satu permasalahan yang ada saat ini adalah penanganan keluhan orangtua yang belum maksimal dikarenakan tidak adanya manajemen keluhan yang baik. Adapun pada penelitian ini menggunakan analisis SWOT (Strenghts, Weakness, Opportunities, dan Threats) dan UML (Unified Modeling Language) untuk menggambarkan model Customer Relationship Management. Dengan demikian Customer Relationship Management berbasis website ini mampu menjadi solusi untuk meningkatkan pelayanan kepada orangtua mahasiswa di STKIP Muhammadiyah Kuningan.

Kata Kunci: CRM, Website, UML, SWOT

The world of education is currently growing very rapidly, where an institution will succeed if it is supported by information technology. But the support from information technology alone is not enough, so experts are needed and the most important thing is management's commitment to establish good relations. Customer Relationship Management is a management model needed in STKIP Muhammadiyah Kuningan to establish good relations between institutions and parents of students in order to increase satisfaction of parental services. One of the problems that exists today is the handling of complaints from parents that have not been maximized due to the absence of good complaints management. This study uses SWOT analysis (Strengths, Weakness, Opportunities, and Threats) and UML (Unified Modeling Language) to describe the model of Customer Relationship Management. Thus website based Customer Relationship Management is a solution to improve service to parents of students at STKIP Muhammadiyah Kuningan.

Keywords: CRM, Website, UML, SWOT.

\section{PENDAHULUAN}

Dalam dunia pendidikan pelanggan dapat dilihat dari berbagai sudut pandang, diantaranya pemakai produk institusi pendidikan, pemakai hasil riset yang dilakukan oleh dunia pendidikan, mahasiswa, calon mahasiswa, alumni,dan orangtua [1]. Berdasarkan konsep pemasaran yang mengutamakan pelanggan, maka pelayanan kepada pelanggan merupakan kunci keberhasilan pemasaran suatu perusahaan. Melalui pelayanan kepada pelanggan, institusi secara langsung dan tidak langsung menjaga pelanggannya agar tidak meninggalkan institusi tersebut. Pelayanan berarti menyangkut dua factor elemen pokok, yaitu factor manusia yang melayani dan factor komunikasi agar yang dilayani 
JURNAL NUANSA INFORMATIKA

Volume 14 Nomor 1, Januari 2020

mendapat kepuasan atas pelayanan yang diberikan. [2]

Instansi pendidikan yang besar dan hebat selalu membangun hubungan yang sangat kuat dengan orangtua mahasiswanya, salah satunya dengan mengaplikasikan model Customer Relationship Management di dalam strategi bisnisnya. Orangtua mahasiswa merupakan aset yang sangat berharga bagi setiap instansi pendidikan. STKIP Muhammadiyah Kuningan berusaha untuk menjaga kepuasan pelayanan orangtua mahasiswa karena jika orangtua mahasiswa merasa puas maka akan berdampak terhadap STKIP Muhammadiyah Kuningan. Keunggulan ini menjadikan STKIP Muhammadiyah Kuningan untuk merancang dan membangun sebuah strategi bisnis yang dapat menciptakan kepuasan orangtua mahasiswa melalui pelayanan, tetapi pada saat ini STKIP Muhammadiyah Kuningan masih kurang mengenal orangtua mahasiswa secara lebih detil.

Oleh karena itu, STKIP Muhammadiyah Kuningan membutuhkan sebuah media berbasis web yang dapat mengelola hubungan antara perusahaan dengan orangtua mahasiswa dan mengaplikasikan model Customer Relationship Management (CRM) agar dapat dimanfaatkan untuk memantau setiap kegiatan dan keinginan orangtua mahasiswa, memberikan pelayanan lebih baik dengan meningkatkan hubungan yang lebih personal dengan orangtua mahasiswa
p-ISSN : 1858-3911, e-ISSN : 2614-5405

https://journal.uniku.ac.id/index.php/ilkom

\section{METODOLOGI PENELITIAN}

Pada penelitian ini menggunakan analisa SWOT (Strenght, Weakness, Opportunities, dan Threaths). SWOT merupakan identifikasi berbagai factor secara sistematis untuk merumuskan strategi perusahaan. SWOT terdiri dari kekuatan, kelemahan, peluang dan ancaman yang dianalisa oleh perusahaan tersebut untuk menentukan langkahlangkah strategis untuk perusahaan tersebut [3].

a. Strength - kekuatan yang dimiliki oleh suatu perusahaan dibandingkan dengan para pesaing. Misalnya kekuatan pemasaran dan penjualan

b. Weakness - kelemahan yang biasanya berbentuk masalah-masalah yang dihadapi oleh suatu perusahaan tersebut dibandingkan dengan perusahaan lainnya.

c. Opportunity - peluang suatu bidang kebutuhan pembeli dimana perusahaan dapat beroperasi secara menguntungkan. Peluang dapat digolongkan menurut daya tariknya dan kemungkinan berhasilnya.

d. Threats - ancaman merupakan tantangan akibat kecenderungan atau perkembangan yang menguntungkan yang akan mengurangi penjualan laba jika tidak dilakukan tindakan defensive (pertahanan)

Ada 4 alternatif strategi yang tersedia yaitu:

a. Stratergi SO - strategi ini dibuat berdasarkan jalan pikiran perusahaan, yaitu dengan memanfaatkan seluruh kekuatan untuk merebut dan memanfaatkan peluang sebesarbesarnya.

b. Strategi ST - strategi ini menggunakan kekuatan yang dimiliki 
JURNAL NUANSA INFORMATIKA

Volume 14 Nomor 1, Januari 2020

perusahaan untuk mengatasi ancaman.

c. Strategi WO - strategi ini diterapkan berdasarkan pemanfaatan peluang yang ada dengan cara meminimalkan kelemahan yang ada.

d. Strategi WT - strategi ini didasarkan pada kegiatan yang bersifat defensive dan berusaha meminimalkan kelemahan yang ada serta menghindari ancaman.

Adapun pengembangan system yang digunakan pada penelitian ini adalah menggunakan requirement prototype dengan alur sebagai berikut : analisa kebutuhan, membuat prototype, menyesuaikan prototype, membuat system, melakukan testing system, menyesuaikan system, dan menggunakan system. Requirement prototype adalah prototipe yang di buat oleh pengembang dengan mendefinisikan fungsi dan sistem prosedur sistem dimana pengguna atau pemilik sistem tidak bisa mendefinisikan sistem tersebut [4]. Dan menggunakan UML (Unified Modeling Language) untuk menggambarkan model customer relationship management

\section{HASIL DAN PEMBAHASAN}

Hasil analisa SWOT yang didapatkan dari penelitian ini adalah:

$\begin{array}{lrl}\text { Strenghts } & \text { 1. } & \text { Memiliki mahasiswa } \\ \text { (Kekuatan) } & \begin{array}{l}\text { yang tersebar cukup } \\ \text { luas di wilayah Jawa } \\ \text { Barat dan Jawa Barat }\end{array} \\ & \text { 2. } \begin{array}{l}\text { Didukung fasilitas } \\ \text { teknologi yang } \\ \text { cukup memadai }\end{array}\end{array}$

3. Antusias orangtua mahasiswa terhadap perkembangan mahasiswa
p-ISSN : 1858-3911, e-ISSN : 2614-5405

https://journal.uniku.ac.id/index.php/ilkom

\begin{tabular}{|c|c|c|}
\hline & 4. & $\begin{array}{l}\text { Dukungan lembaga } \\
\text { terhadap } \\
\text { peningkatan } \\
\text { pelayanan } \\
\text { orangtua }\end{array}$ \\
\hline \multirow[t]{2}{*}{$\begin{array}{l}\text { Weakness } \\
\text { (Kelemahan) }\end{array}$} & 1. & $\begin{array}{l}\text { Kurangnya } \\
\text { pemanfaatan } \\
\text { teknologi untuk } \\
\text { meningkatkan } \\
\text { pelayanan kepada } \\
\text { orangtua }\end{array}$ \\
\hline & 2. & $\begin{array}{l}\text { Kendala dalam } \\
\text { penyampaian hasil } \\
\text { akademik mahasiswa } \\
\text { kepada orangtua } \\
\text { mahasiswa }\end{array}$ \\
\hline \multirow[t]{3}{*}{$\begin{array}{l}\text { Opportunities } \\
\text { (Peluang) }\end{array}$} & 1. & $\begin{array}{l}\text { Penjaringan } \\
\text { mahasiswa yang } \\
\text { diperluas ke berbagai } \\
\text { daerah }\end{array}$ \\
\hline & & $\begin{array}{l}\text { Dukungan sarana } \\
\text { dan prasarana yang } \\
\text { semakin membaik }\end{array}$ \\
\hline & 3. & $\begin{array}{lr}\text { Tren yang } & \text { semakin } \\
\text { beragam } & \text { dalam } \\
\text { melayani orangtua } & \\
\text { mahasiswa } & \end{array}$ \\
\hline \multirow[t]{3}{*}{$\begin{array}{l}\text { Threats } \\
\text { (Ancaman) }\end{array}$} & & $\begin{array}{lr}\text { Kinerja } & \text { lembaga } \\
\text { dalam } & \text { pelayanan } \\
\text { kepada orangtua } & \text { mahasiswa dinilai } \\
\text { kurang maksimal }\end{array}$ \\
\hline & & $\begin{array}{l}\text { Dunia pendidikan } \\
\text { semakin bersaing } \\
\text { dalam meningkatkan } \\
\text { pelayanan }\end{array}$ \\
\hline & & $\begin{array}{l}\text { Kondisi ekonomi } \\
\text { masyarakat yang } \\
\text { belum stabil }\end{array}$ \\
\hline
\end{tabular}

\section{Identifikasi Masalah}

STKIP Muhammadiyah Kuningan tidak maksimal dalam memanfaatkan teknologi 
JURNAL NUANSA INFORMATIKA

Volume 14 Nomor 1, Januari 2020
p-ISSN : 1858-3911, e-ISSN : 2614-5405

https://journal.uniku.ac.id/index.php/ilkom

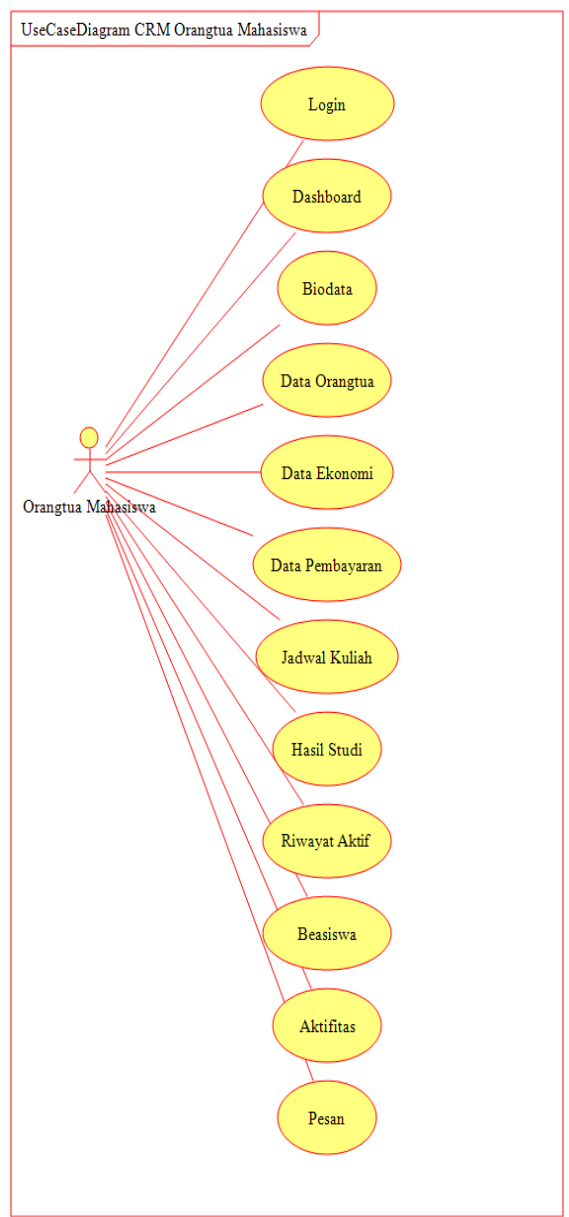

Gambar 1. Usecase Diagram CRM

2. Activity Diagram

Activity Diagram menggambarkan spesifikasi proses bisnis, dan memberikan pandangan dari proses bisnis yang terjadi [5].
a. Activity Diagram Login; menggambarkan aktifitas user untuk login kedalam system. 
JURNAL NUANSA INFORMATIKA

Volume 14 Nomor 1, Januari 2020

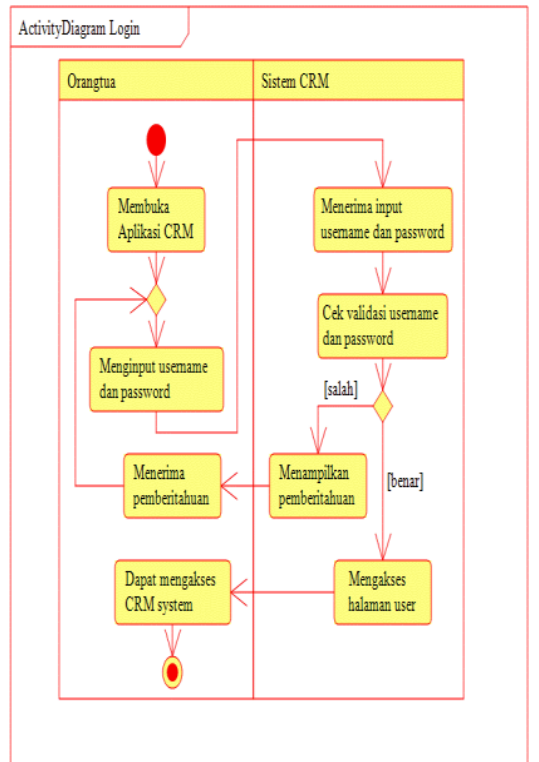

Gambar 2. Activity Diagram Login

b. Activity Diagram Dashboard; menggambarkan aktifitas user ketika mengakses halaman dashboard.

ActivityDiagram Dashboard

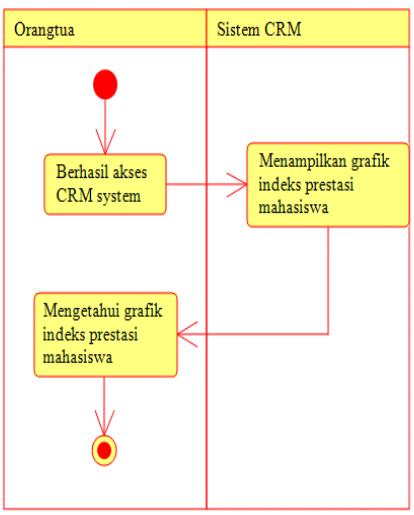

Gambar 3. Activity Diagram Dashboard

c. Activity Diagram Biodata; menggambarkan aktifitas user ketika mengakses halaman Biodata.
p-ISSN : 1858-3911, e-ISSN : 2614-5405

https://journal.uniku.ac.id/index.php/ilkom

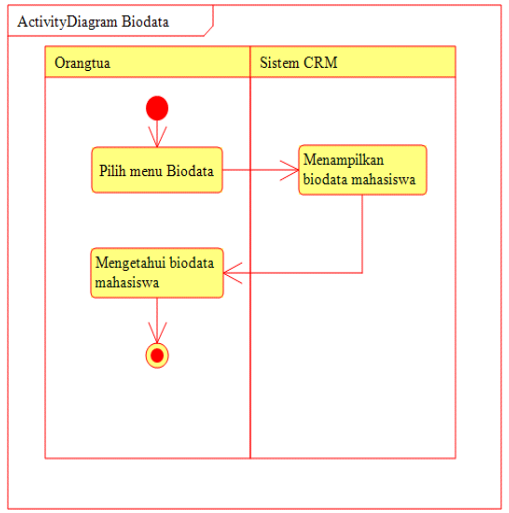

Gambar 4. Activity Diagram Biodata

d. Activity Diagram Data Orangtua ; menggambarkan aktifitas user ketika mengakses halaman Data Orangtua.

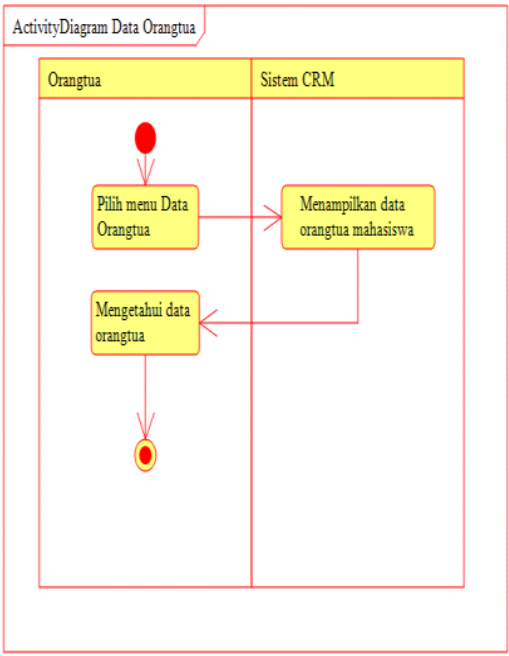

Gambar 5. Activity Diagram Data Orangtua

e. Activity Diagram Jadwal Kuliah; menggambarkan aktifitas user ketika mengakses halaman Jadwal Kuliah. 
JURNAL NUANSA INFORMATIKA

Volume 14 Nomor 1, Januari 2020

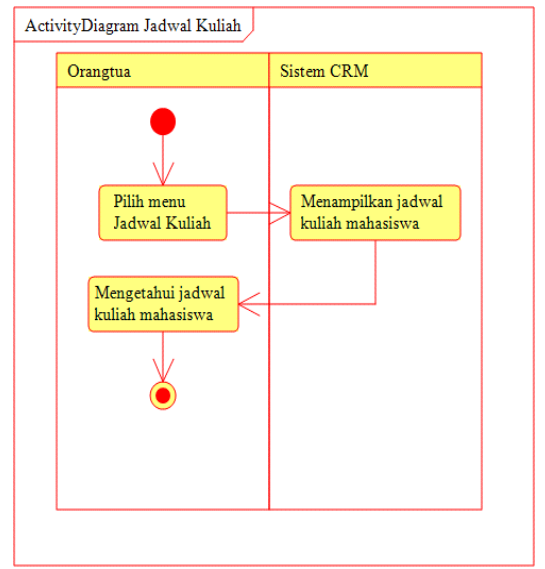

Gambar 7. Activity Diagram Data Jadwal Kuliah

f. Activity Diagram Hasil Studi; menggambarkan aktifitas user ketika mengakses halaman Hasil Studi.

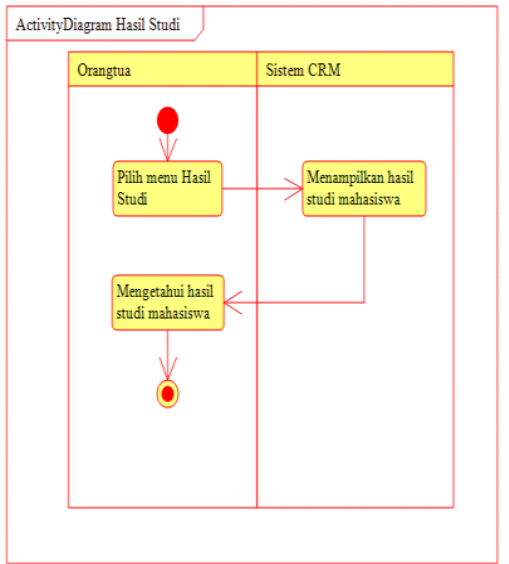

Gambar 8. Activity Diagram Hasil Studi

g. Activity Diagram Beasiswa; menggambarkan aktifitas user ketika mengakses halaman Beasiswa.
p-ISSN : 1858-3911, e-ISSN : 2614-5405

https://journal.uniku.ac.id/index.php/ilkom

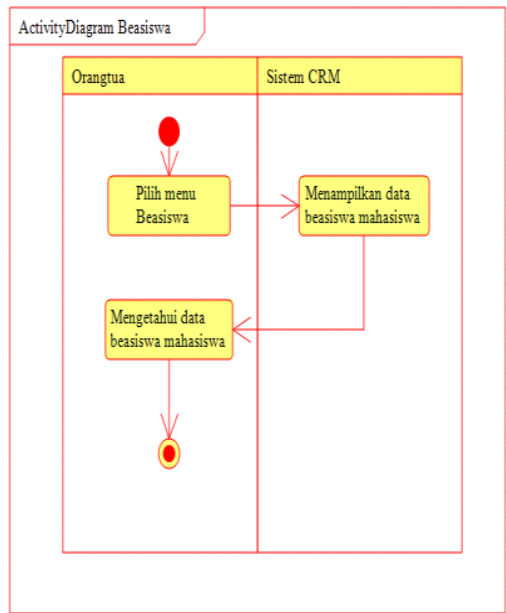

Gambar 10. Activity Diagram Data Beasiswa

Tampilan rancangan layar produk Customer Relationship Management berbasis Website yang dapat diakses pada url http://parent.upmk.ac.id

1. Tampilan layar Login

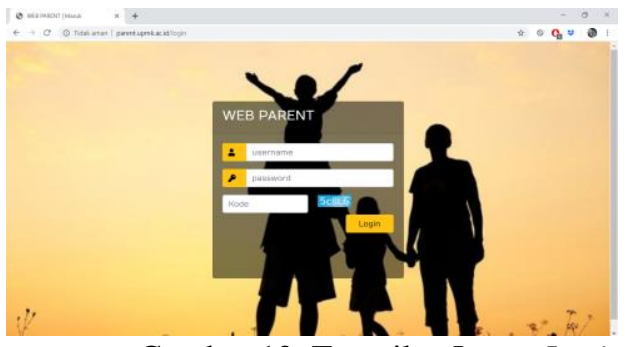

Gambar 12. Tampilan Layar Login

\section{Tampilan layar Dashboard}

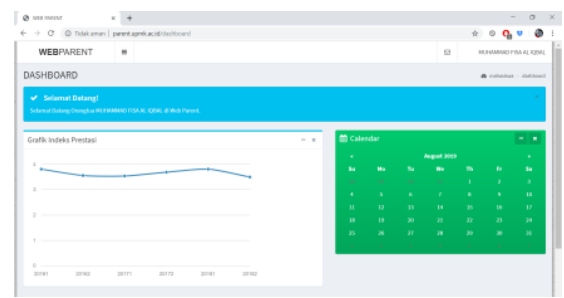

Gambar 13. Tampilan Layar Dashboard 
JURNAL NUANSA INFORMATIKA

Volume 14 Nomor 1, Januari 2020

3. Tampilan layar Menu

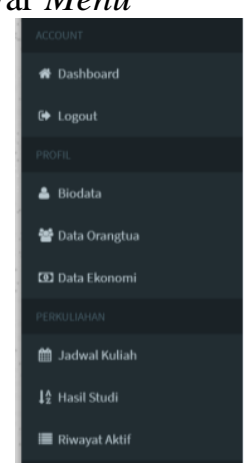

Gambar 14. Tampilan Layar Menu

4. Tampilan layar Jadwal Kuliah

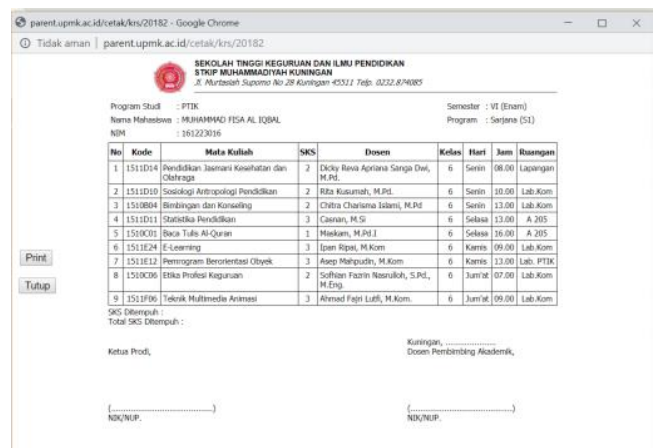

Gambar 19. Tampilan Layar Jadwal Kuliah

5. Tampilan layar Hasil Studi

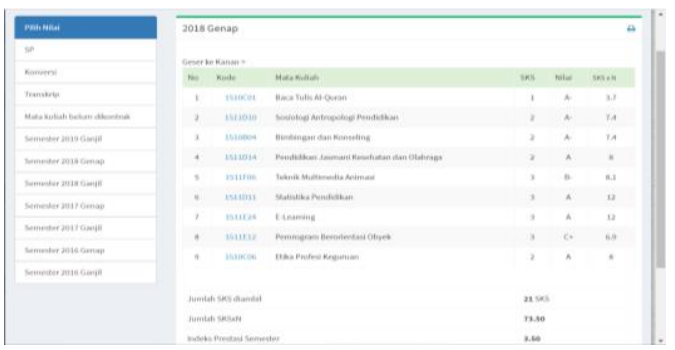

Gambar 21. Tampilan Layar Hasil Studi
p-ISSN : 1858-3911, e-ISSN : 2614-5405

https://journal.uniku.ac.id/index.php/ilkom

6. Tampilan layar Beasiswa

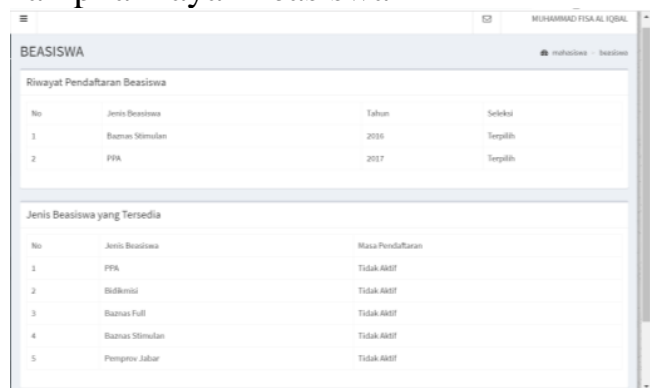

Gambar 22. Tampilan Layar MenuBeasiswa

4. KESIMPULAN

Dari pembahasan tersebeut dapat disimpulkan dengan dengan adanya website myparent dihrapkan orangtua dapat dengan mudah mengakses dan mengetahui aktivitas akademik mahasiswa.

\section{DAFTAR PUSTAKA}

[1] Hamidin, Dini. 2018. Model Customer Relationship di Institusi Pendidikan. Seminar Nasional Aplikasi Teknologi Informasi 2008. ISSN: 1907-5022.

[2] Haryono, Budi. 2013. How to Manage Customer Voice. Yogyakarta : Andi Publisher

[3] Indrajani. 2007. Analisis dan Perancangan Sistem Penjualan Berbasis Web pada PT. Sarang Imitasi. Seminar Nasional Teknologi 2007. ISSN: $1978-9777$

[4] Mark W. McElroy. 2000. Knowledge and Innovation: Journal of the KMCI, Vol. 1 : 43-67.

[5] Marakas, George M. 2006. System Analysis and Design Analitical Approach 2th Edition. The McGraw Hill Companies Inc, Newyork. 